\title{
HOW DOES DIGITAL PROGRAMS HELP TO UNDERSTAND URBAN EVOLUTION THE STUDY CASE OF A PORTUGUESE MEDITERRANEAN VILLAGE
}

\author{
M. Pacheco a, T. Heitor a \\ a IST, Instituto Superior Técnico - Universidade Técnica de Lisboa, Av. Rovisco Pais 1049-001 Lisbon, Portugal \\ (mbatistapacheco@hotmail.com, teresa@civil.ist.utl.pt)
}

KEY WORDS: Mediterranean Architecture, Urban History, Urban Morphology, Visual and Spatial Network Analysis, Depthmap Software, Town of Fuseta

\begin{abstract}
:
The cultural heritage of the fisherman's town of Fuseta, on the southern Portugal, is an interesting example of Mediterranean vernacular architecture. Totally built in just one-step at the turn and the 19th to 20th centuries, the historic centre presents a homogeneous urban fabric characterized by a typology of house covered by vaults' terraces, and pyramidal roofs, strategically located. Nowadays, the urban network extrapolates the original historic centre to the involving areas, with a demarcated rural structure.

This paper aims to reflect on the contribution of space syntax descriptive model, an alpha numeric's calculation software (Depthmap Software), based on visual and spatial networks' analysis, to the study of the urban evolution.

The almost non-existence of bibliography related to the urban history of this territory, enforces the use of alternative methods to increase the architectural morphology's theories and other theoretical approaches focused on the reading of urban territories.

The Depthmap modelling of the town's digital cartographics allowed the production of maps that expresses parameters and urban concepts universally defined. The main question consists in how deep this new urban modelling information is and how useful are these maps or they just descriptive.

In conclusion, the appliance of the Depthmap Software on the study of the Fuseta's urbanism made it possible to draw a reliable parallel between the unknown urban characteristics of the 20th century beginning with the well-known structure of today, at same level of measurements, detailing, information and parameterization.
\end{abstract}

\section{INTRODUCTION}

\subsection{The Mediterranean Town of Fuseta}

Fuseta is a fisherman's town in Algarve, the southern region of Portugal. It was built between the 19th and the middle of 20th century (although the first settlements go back to 16th century), and like other villages on Algarve's coast, has Mediterranean characteristics. The homogeneous urban fabric of the historical centre is characterized by a typology of house covered by vaults', terraces, and pyramidal roofs, strategically placed, both with an important bioclimatic performance. The main aspects are still maintained due to its geographical location bounded by a lagoon, a river and a railway, preserving it from deep changes.

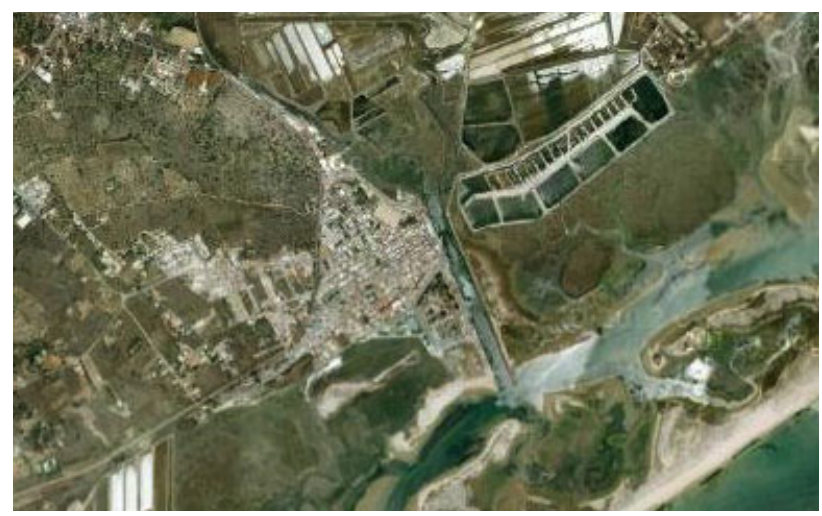

Figure 1: Actual aerial view of Fuseta's town. (Image (C2012 Google Aerodata International Surveys Cnes/Spot Image. Digital Globe, GeoEye, IGP/DGRF)

\subsection{The challenge of Fuseta's urban evolution}

The application of space syntax descriptive model software (Depthmap Software) to study the urban evolution of the town is connected with the problem of the lack of primary sources', which are necessary to know the morphologic characteristics of the territory in the past and compare it with the present urbanism, establishing the same kind of approach and evaluation. Therefore, the aim of using Depthmap Software is to generate a group of digital information of Fuseta, both about the past and the present network, which will make possible to compare these different periods and determine the urban evolution, with these new sources.

The new information provided by Depthmap Software brings a different type of reading of the territory, which is indispensable to develop and inquire into the studies done by other authors in the fields of urbanism, architecture, anthropology and sociology. As important examples of those researches, it should be mentioned the work produced by the team of the Inventory of Vernacular Architecture in Portugal during the 50's of last century (Martins et al., 2004), publishing the first urban plan and architectural details of Fuseta's houses' typology; the anthropological approach to the village's population (Ramos de Oliveira, 1971), describing the existence of Seamen and Landsmen's groups and neighbourhoods, according with their economical activities; and recently, the study about the urban and architectonic evolution of the village (Pacheco, 2009), which propose an empiric interpretation based on urbanism concepts to define the evolution network model, can now be deeply revised. 


\section{MODELLING THE EVOLUTION OF URBAN MORPHOLOGY}

\subsection{From orthogonal old town structure to the new organic streets}

To understand the evolution of Fuseta urban morphology it was necessary to consider a time interval of a century (from 1900 to approximately 2010), which mean comparing the morphological conditions since its beginning (when the provisory wooden houses were substituted for masonry houses) with modern construction. This comparison will inform how the urban expansion changed the old town's structure, namely how the orthogonal plan was affected with the extension of the main streets and planning of new ones, over the adjacent lagoon area.

The old town is composed by an orthogonal urban fabric with long axes of northeast - southwest orientation, with parallel streets crossed by perpendicular axes, adapted to the differences of topography, sun exposition, winds and waves direction. Concerning the urban fabric extension during the last decades, the most important action consists on the east riverside new waterfront street and the new urban areas at south, with an organic delineation because its confinement to the riverside and the lagoon, contrasting with the old town.

\subsection{Methodological procedures}

To compare the old urban core with the new urban area, three different models were developed: 1) the urban core at the beginning of the 20th century, 2) the urban core in the $21 \mathrm{st}$ century and 3) the current town's area. This urban analysis was followed by a local scale analysis, where the main squares were compared in both periods.

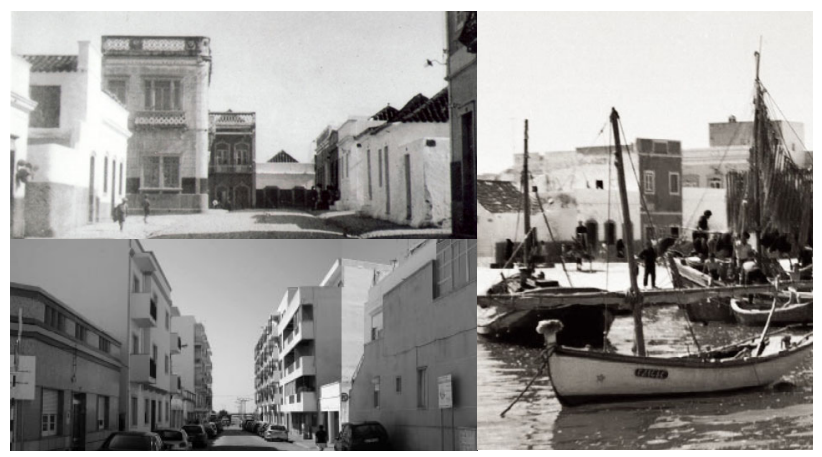

Figure 2: Main street with northeast - southwest orientation on the beginning of 20th century and on the $21^{\text {st, }}$, on the left side, and the river front on the 20 th century, on the right side.

Starting with a 2D digital cartography in a CAD format model of the actual village's urban fabric, the urban fabric was reconstructed as it should be during the beginning of the 20th century. Although the urban core has the same plan, the surrounding streets did not exist on that time. This reconstruction was developed according with the map published on the Inventory of Vernacular Architecture in Portugal, during the 50's of last century (Martins et al., 2004) and photos taken by the population during the same period.

Both cartographic modelings (of 20th and 21st centuries) in a $2 \mathrm{D}$ vector drawing format were simplified in the way that each street is represented by a line or lines with the longest possible, and squares transformed in crossed lines. The success of this proceeding depends of the knowledge that author has of the place. The lines' set, represented in the same layer, were imported to the alpha numeric's calculation software (UCL Depthmap Software), originating Depthmap graph files.

The Depthmap Software, a space syntax descriptive model based on visual and spatial networks' analysis, generate sets of two kinds of maps: a) axial maps, which analyzes concepts like connectivity, integration, synergy, intelligibility, entropy and b) visibility maps, which evaluates the step depth's parameter, which mean the shortest path from a chosen point of the system, in this study the main squares, among other parameters in both type of maps.

\subsection{The axial maps}

Importing the 2D-CAD format of the axial map (composed by lines which correspond to the urban plan) to the Depthmap Software, an automatic graph is generated with connectivity's measures. The graph is also used to calculate other syntactic measures by running different analysis' parameters.

\subsubsection{Connectivity and segments' number}

The axial map of connectivity describes the number of lines that each axe intersects with. From the 20th century to $21 \mathrm{st}$, the connectivity increased slightly, around 113 percent. However, comparing the urban core with actual village's area, connectivity decreased more than 69 percent. Regarding to the segments' number of each model, in a range of a century, the urban core increased 177 percent, and the urban area increased up to 400 percent.

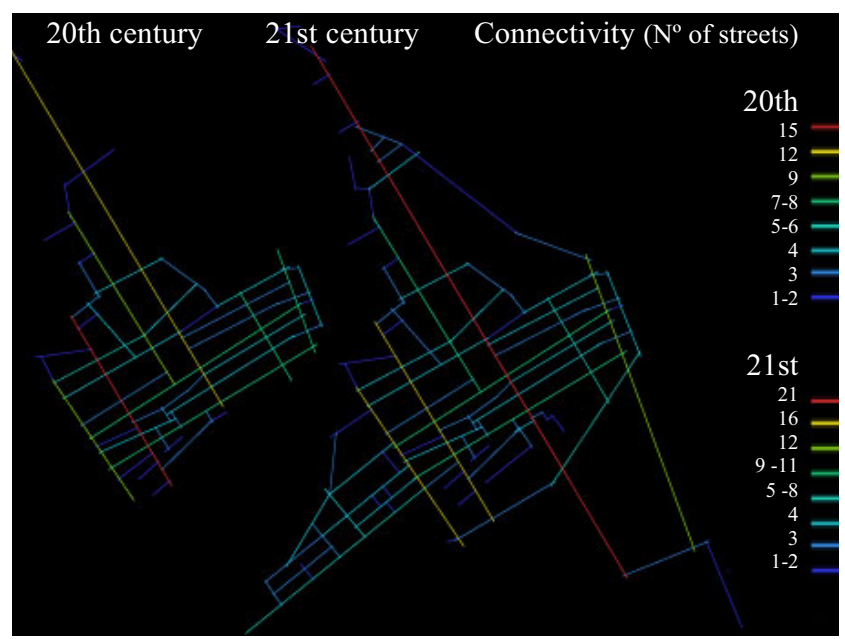

Figure 3: Connectivity's axial maps of the urban centre on the beginning of 20 th and 21 st centuries, respectively.

\subsubsection{Global and local Integration}

On the global integration map it is analyzed the potential of topological accessibility calculated for the entire system and considering the global properties, Rn, where the variable " $R$ ", correspond to the radius, which means how many axes we account from any place of the system, and " $n$ " the unlimited number of possible connections. We also calculated the local integration map, at a third level, R3 (radius 3) which coincides with the potential properties at a local scale, where it is 
considered only to three lines that follow in any direction from a certain line (Hillier, 1984).

When we compare the global integration to the urban core, in range of a century, we verify that the level of integration remains the same (100 percent) but when we compare the urban core with the new urban area, this parameter reduces drastically (56 percent) which is justified by the rural character outside the perimeter of historic core.

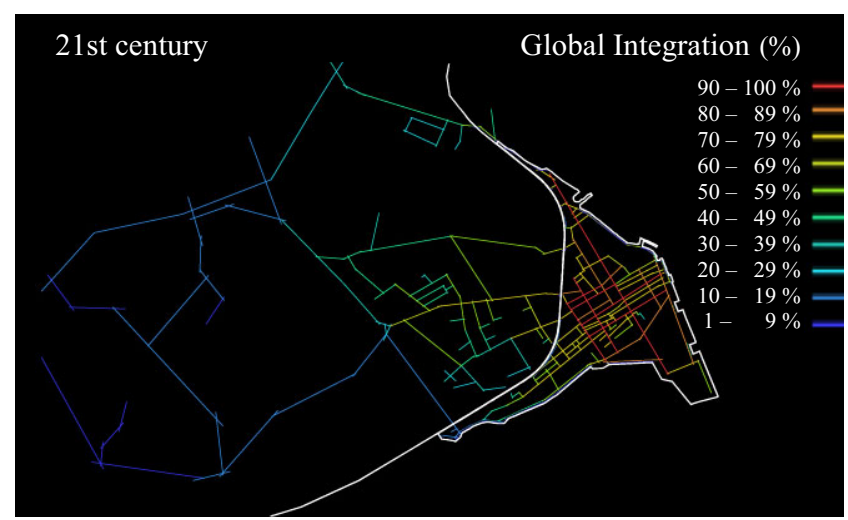

Figure 4: Global integration's axial map of the town's area.

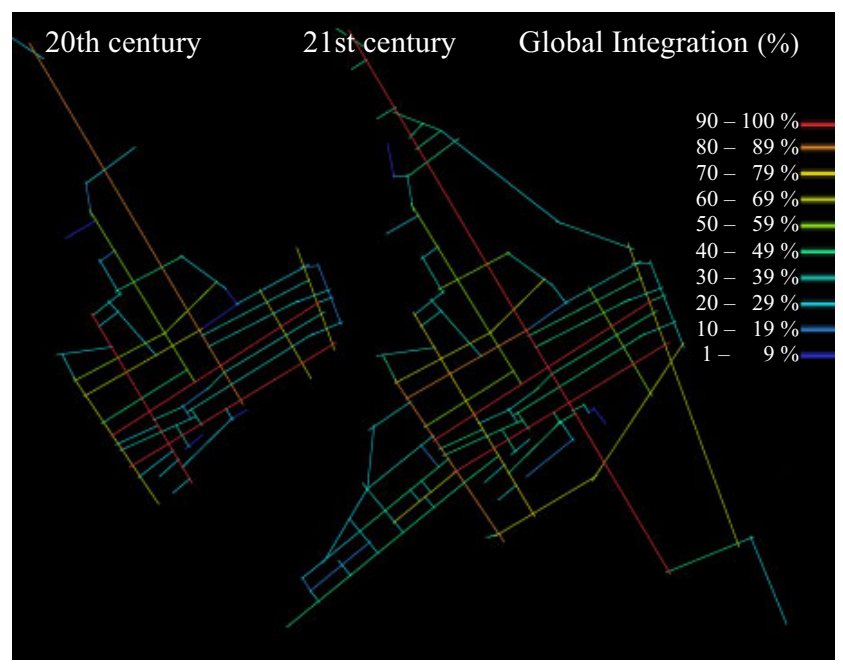

Figure 5: Global integration's axial map of the urban centre, on the beginning of 20th and 21 st centuries.

On local integration, assuming R3 (radius 3), there was a slight increase of 105 percent, due to the opening of a residential block at south part of the urban plan, increasing the northsouth main axe. More significantly is the comparison between urban core and urban area, were it is observed reduction of 75 percent of the local integration.

We come to the conclusion that the territorial expansion of the last hundred years has not contributed to increase integration, which should be a point to improve on future planning.

\subsubsection{Intelligibility}

The Intelligibility concept applied to space analysis corresponds to the correlation between connectivity and global integration's values of the axes in a specific system, resulting in the coefficient of determination, which indicates the degree of dependence of one variable to another.

This coefficient is closely related to the existence of long axes that cross the whole system. If the system has just a few global axes, there is less changes to be intelligible, and the global local relationship is compromised because of the difficulty to realize the entire system (Medeiros, 2006).

The perception is made by parts and consequently restricted to certain areas of space. This principle is associated with the notions of topological perception (Kohlsdorf, 1996) concerning to the difficulties or facilities in the orientation and location of the people passing through urban space. So, the addition of new segments or changes in the geometry of the city tends to cause fragmentation in the configuration, by breaking the continuity of space (Medeiros, 2006). That's why on the study case the intelligibility factor is the most decreased.

Comparing the urban core with the village's area, intelligibility dropped 36 percent. This is due to the expansion of an orthogonal urban core to an organic fabric with rural characteristics.

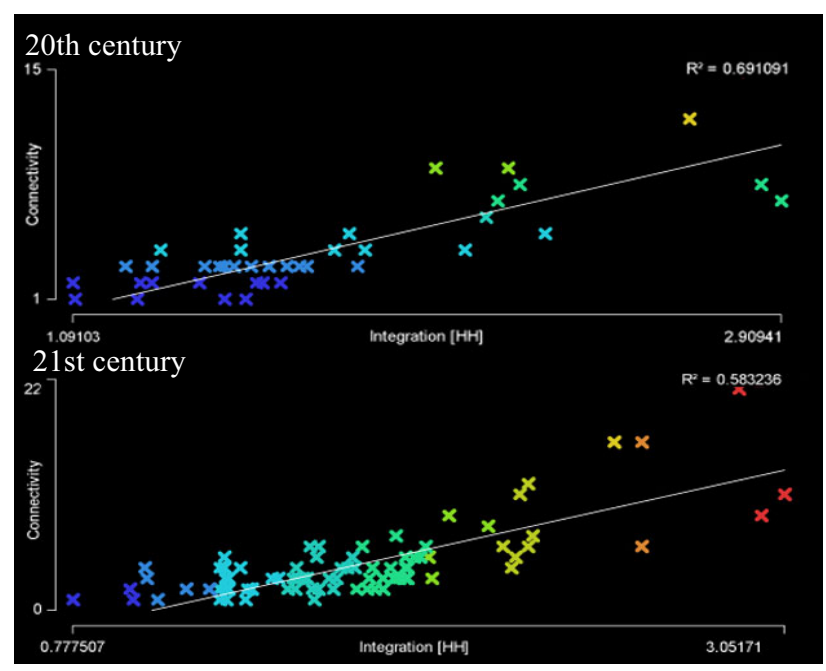

Graphic 6: Intelligibility's graphs of urban centre, on the beginning of 20th and 21st centuries, respectively. Represented points correspond to segments on the axial map.

\subsubsection{Synergy}

Concerning to the study of space syntax, synergy consists in the synchronization degree of the balance between global and local integration's levels, measuring the dependence of a variable to another. This parameter is analysed by the coefficient of determination for the correlation between the values of global integration (Rn) to local integration (R3) for all axes of the system (Medeiros, 2006). On this study, the parameter comes more significantly when comparing the urban core with the urban area, reducing 78 percent, in view of the comparison of urban core during the 20th and 21 st century, with a reduction of just 95 percent. 


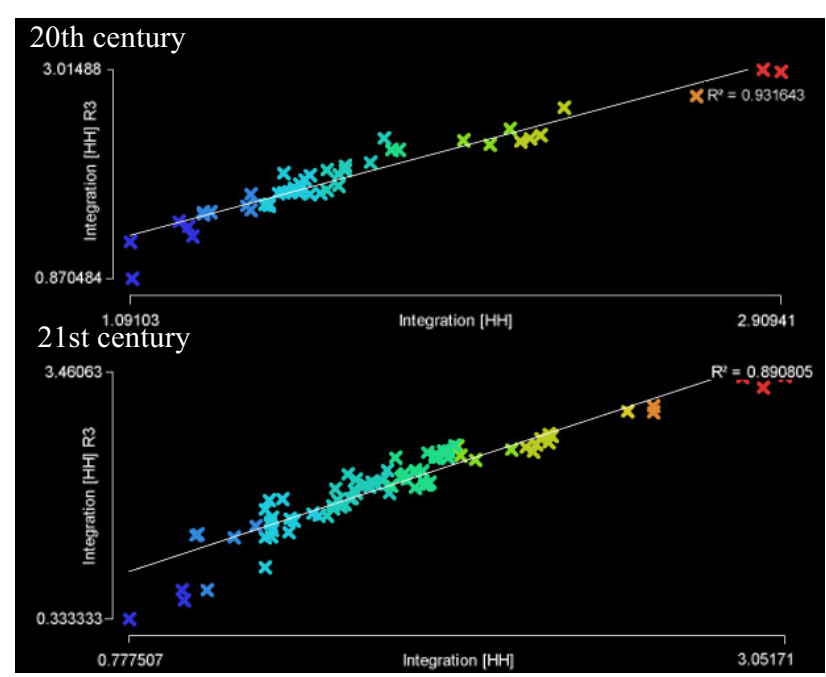

Graphic 7: Synergy's graphs of urban centre, on the beginning of 20th and 21st centuries, respectively. Represented points correspond to segments on the axial map.

\subsection{The Visibility maps}

The visibility maps analysis (known also as VGA maps) gives the opportunity to make a local interpretation of the model, which in the study of specific points of the network is appropriate. The local model measures are based on the relationships between each node and the nodes directly connected to it. Through the visibility graph (VGA step-depth metric measures map) are calculated for each node, the shortest path to any point within the graph, considering the fewest number of turns.

\subsubsection{Visibility maps procedures}

The VGA map is created by importing the 2D-CAD village's urban plan into the Depthmap Software and then submitting to a grid of points that will be part of the graph over which the analysis' parameters will run. The grid spacing can be chose between 1 and 5 , even though default spacing can be set automatically according to the dimensions of the drawing and its complexity (to this study it was applied a grid spacing of 5, due to the orthogonal plan). After apply the grid, the visibility graph is created. The connections representing the visibility of points are colored according to how many other locations are visible from it. The range runs from blue (for low) through green and yellow to red (many visible locations).

Once the graph is created, simple measures can be analyzed, as the step depth, or the distance (visibility, metric or angular) from one point to all other locations. Step depth illustrates the number of steps (changes of direction) it would take to get from the selected location to any other location in the graph. In this study it was choose the town's main squares.

\subsubsection{Step Depth visibility's maps of main squares}

On this point of the study, the aim is to compare the step depth VGA's parameters of the urban core's main squares of 20th and 21 st centuries, and analyze the spatial relationship between them and their changes on time. According to some testimonials, the two communities of Fuseta (Seamen and Landsmen) were separated by their economic activities, lived in isolated neighborhoods and had different squares as central points (Ramos de Oliveira, 1971). Before the urban expansion, during the 20th century, the Seamen Square dominate the southwest area of the village, corresponding to the high point, the hill, and the access to lagoon's territory, whereas the Landsmen Square controls the central area on northeast and main entrance in town.

However, we can recognize that the main point since last century is the Dock Square, where ends the main streets of each neighborhoods, making a link between both spaces. This quality is more perceptible on the 21 st century graph, with the expansion axes along the riverside to the new beach's area.

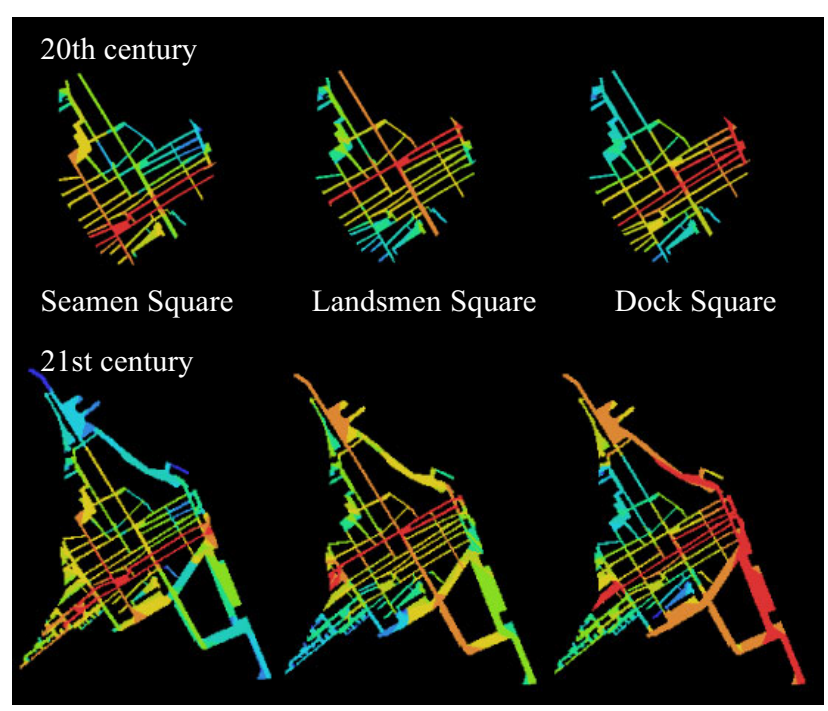

Figure 8: Metric step depth visibility's maps of main squares, on the beginning of 20th and 21 st centuries.

\section{CONCLUSIONS}

The analysis of axial maps of Fuseta's urban core and urban area in the last hundred years, allowed us to understand that the original orthogonal structure of the urban fabric core lost their characteristics with the growth to new rural areas, following an organic design induced by natural limits.

Most of the parameters studied had an increase when comparing inside the urban core, which means that the structure has the capacity to absorb the new changes without losing its design characteristics. In respect of the evolution of urban area in its totality, most of parameters deeply declined, revealing that recent organic design is not so sewn to the old orthogonal fabric, having negative holes and interruptions.

With regards to the visibility maps, they answered some previous questions made about the characteristics of the squares, their relationship and its function on global system. The underlining of other potential areas with high capacity of connections that they are not being exploited yet, are also a positive aspect.

The production of axial and visibility maps substituted for the lack of documents, making it possible, from now and in the future, to characterize urban morphology during past periods, without information sources. 


\begin{tabular}{l|l|l|l} 
Parameters (average) & $\begin{array}{c}\text { Urban core } \\
\text { 20th Century }\end{array}$ & $\begin{array}{c}\text { Urban core } \\
\text { 21st Century }\end{array}$ & $\begin{array}{c}\text { Urban Area } \\
21 \text { st Century }\end{array}$ \\
\hline Connectivity & 3,85 & $\uparrow 4,34$ & $\uparrow 2,99$ \\
\hline Global Integration & 1,71 & $\uparrow 1,7$ & $\uparrow 0,74$ \\
\hline Local Integration & 1,93 & $\uparrow 2,04$ & $\uparrow 1,53$ \\
\hline Global Entropy & 1,29 & $\uparrow 1,24$ & $\uparrow 1,32$ \\
\hline Local Entropy & 0,69 & $\uparrow 0,58$ & $\uparrow 0,21$ \\
\hline Synergy & 0,93 & $\uparrow 0,89$ & $\uparrow 0,7$ \\
\hline Intelligibility & 0,69 & $\uparrow 0,58$ & $\uparrow 0,21$ \\
\hline Controllability & 0,24 & $\uparrow 0,24$ & $\uparrow 0,33$
\end{tabular}

Table 9: Comparison of parameters analysed by UCL Depthmap Software, concerning to the urban core on the beginning of 20th and 21 st centuries and today's urban area.

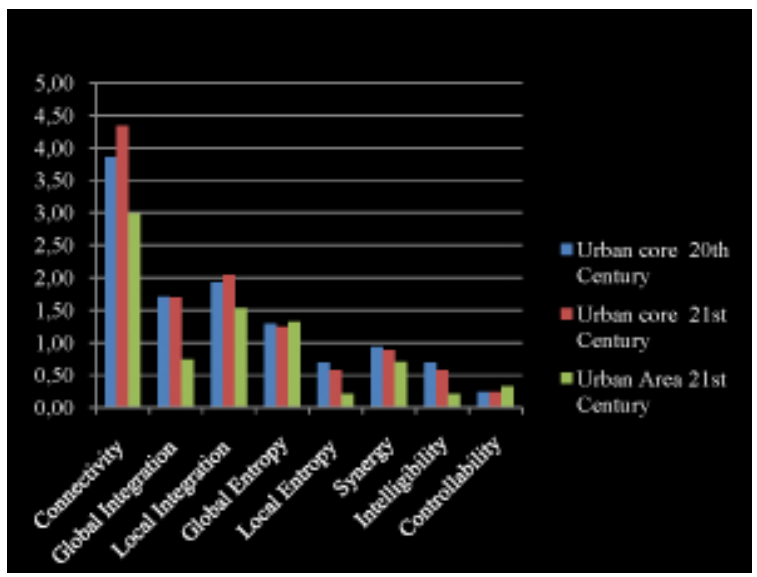

Graphic 10: Comparison of parameters analysed by UCL Depthmap Software concerning to the urban core on the beginning of 20th and 21 st centuries and today's urban area.

Depthmap software is an important tool for predicting the future of urban evolution, to identify the potential and problematic areas and to simulate projects and urban interventions, test the ideas of urbanism and analyze the behavior of the urban organism when subject to changes, revealing being a useful tool for multiple professional research teams.

In conclusion, this study demonstrates the advantages of joint working procedures of new technologies in parallel with traditional methods of research, helping to understand, preserve and intervene in cultural heritage.

\section{REFERENCES}

\section{References from Books:}

Feio, M., 1949. Le Bas Alentejo et l'Algarve, International Congress of Geography, Lisbon, Portugal.

Goldfinger, M., 1993. Arquitectura Popular Mediterránea, Gustavo Gili, Barcelona, Spain.

Hillier, B. (et al), 1984. The social logic of space, Cambridge University Press, London, United Kingdom.
Hillier, B., 1996. Space is the machine, Cambridge University Press, London, United Kingdom.

Kohlsdorf, M., 1996. A apreensão da forma da cidade, EdUnB, Brasilia, Brazil.

Martins, A. (et al.), 2004 (1961). Zona 6 - Alentejo e Algarve. In Arquitectura Popular em Portugal, Ordem dos Arquitectos, Lisbon, Portugal. Vol.II, pp.241-359.

Medeiros, V., 2006. Urbis Brasiliae ou sobre cidades do Brasil, Faculdade de Arquitectura e Urbanismo - Universidade de Brasilia. Brasilia, Brazil

Pacheco, M., 2009. A Evolução Urbana e Arquitectónica da Fuseta, Instituto Superior Técnico - UTL, Lisbon, Portugal.

Ramos de Oliveira, C., 1971. Fuzeta: uma abordagem antropológica, Instituto Superior de Ciências Sociais e Política Ultramarina, Lisbon, Portugal.

Turner, A., 2004. Depthmap 4: A researcher's handbook, Bartlett School of Built Environment, London, United Kingdom.

\section{References from websites:}

Aerodata Internationa Surveys, 2012. Google maps. Cnes/Spot image, DigitalGlobe, GeoEye, IGP/DGRF.

http://www.google.com (accessed 20 May 2012)

PNUM/Rede Portuguesa de Morfologia Urbana http://pnum.fe.up.pt/pt (accessed 20 May 2012)

UCL DepthMap Software http://www.spacesyntax.net/software/ucl-depthmap/(accessed 20 Feb. 2012)

\section{ACKNOWLEDGEMENTS}

The present paper is funded by the FCT - Foundation for Science and Technology - Scholarship for Advanced Studies $\mathrm{PhD}$, within the Integrated Doctoral Program in Architecture at the Department of Advanced Studies in Architecture at the IST - UTL: Instituto Superior Técnico - Technical University of Lisbon. 
